Abstracta Iranica Abstracta Iranica

Revue bibliographique pour le domaine irano-aryen

Volume 25 | 2004

Comptes rendus des publications de 2002

\title{
Les femmes iraniennes entre islam, Etat et famille. Paris, Maisonneuve et Larose, 2002, 318 p., phot., bibl., index.
}

Jean-Pierre Digard

\section{(2) OpenEdition}

Journals

Édition électronique

URL : http://journals.openedition.org/abstractairanica/5158

DOI : 10.4000/abstractairanica. 5158

ISSN : 1961-960X

Éditeur :

CNRS (UMR 7528 Mondes iraniens et indiens), Éditions de l'IFRI

Édition imprimée

Date de publication : 15 mai 2004

ISSN : 0240-8910

Référence électronique

Jean-Pierre Digard, "Les femmes iraniennes entre islam, Etat et famille. Paris, Maisonneuve et Larose, 2002, 318 p., phot., bibl., index. », Abstracta Iranica [En ligne], Volume 25 | 2004, document 326, mis en ligne le 15 mars 2006, consulté le 25 septembre 2020. URL : http://journals.openedition.org/ abstractairanica/5158; DOI : https://doi.org/10.4000/abstractairanica.5158

Ce document a été généré automatiquement le 25 septembre 2020.

Tous droits réservés 


\title{
Les femmes iraniennes entre islam, Etat et famille. Paris, Maisonneuve et Larose, 2002, 318 p., phot., bibl., index.
}

\author{
Jean-Pierre Digard
}

1 Ce livre salubre entreprend de répondre à une question, entres autres, qui préoccupe à juste titre l'opinion occidentale : pourquoi des femmes adhèrent-elles aux mouvements islamistes? La réponse - parce que ces mouvements leur offrent une posture militante et, donc, une occasion de sortir de la sphère privée et de s'investir dans la vie active, de s'autonomiser fut-ce au prix du voilement - ne manquera pas de susciter, comme toujours, l'ire des féministes (iraniennes résidant en Occident aussi bien qu'occidentales). Du moins cette réponse est-elle ici fondée sur une documentation de première main et sur une argumentation qui rejette tout autant les approches culturalistes et essentialistes occidentales que les idéologies islamistes vides de tout proj et de société.

2 Un premier chapitre propose un «tour d'horizon » de la place des femmes dans la lutte des Iraniens pour l'avènement d'un régime démocratique et de la séparation entre Etat et religion, en distinguant trois périodes: révolutionnaire (1979-1988), de reconstruction (1989-1997), de développement politique (depuis 1997, année marquée par l'élection du président Khâtami). Ces trois périodes sont reprises et détaillées dans les chapitres suivants. Le chapitre II examine les raisons qui ont conduit les femmes à participer au renversement de la monarchie : il s'agit principalement de la confiscation du discours féministe par l'Etat autoritaire, qui avait entravé l'émergence de mouvements indépendants des femmes. Traitant des débuts de la République islamique, le chapitre III montre qu'à défaut de pouvoir appliquer l'islam dans tous les domaines, le nouveau régime a mis l'accent sur un domaine qui faisait l'unanimité (des hommes) : le droit de la famille et la féminité, faisant de l'obligation du port du voile le premier signe de l'islamisation du pays. Face à cette islamisation forcée, les femmes 
adoptent des comportements nouveaux (chapitre IV), dans les domaines démographique (limitation des naissances), familial (vis-à-vis des enfants, des maris), de la formation et professionnel (scolarisation, études supérieures, investissement dans le travail). Les femmes-mères paient au prix fort la mise en œuvre de ces stratégies ; mais grâce à celles-ci, elles réussissent à transmettre à leurs enfants une véritable contre-culture.

3 Le " puéro-centrisme ", nouveau type de violence subie par les mères décrit au chapitre $\mathrm{V}$, constitue, selon l'A., l'un des changements les plus importants intervenus dans la vie des familles. Il consiste en une véritable obsession parentale (maternelle surtout) de satisfaction des «besoins" voire des caprices des enfants, qui entraîne l'instrumentalisation des parents par les enfants et développe chez ceux-ci consumérisme et individualisme (on saisit mal les causes spécifiques de ce phénomène qui ne semble, du reste, pas propre à l'Iran...). Toujours est-il que ces faits et d'autres ont fait prendre conscience aux femmes qu'elles partagent des intérêts divergents de ceux de leurs conjoints. La solidarité féminine s'est développée et se manifeste dans des luttes multiformes des femmes pour résister à l'islamisation dans tous les domaines : politique, professionnel, intellectuel, artistique, sportif. Il commence à en résulter une certaine amélioration de la condition des femmes, dans un cadre qui dépasse aujourd'hui celui de la stricte intelligentsia pour s'étendre à une grande partie de la population féminine. Par ailleurs, le fossé s'est creusé entre les femmes et les dirigeants iraniens, modérés aussi bien que radicaux; les compromis entre les deux camps, conclus au détriment des femmes, ont contribué à autonomiser celles-ci par rapport au pouvoir et à les convaincre de la nécessité de poursuivre leur lutte.

4 Livre d'actualité, donc, mais fondé sur des enquêtes sociologiques approfondies sur le terrain, nourri d'une problématique originale et aux vues décapantes malheureusement déparé par une édition sans soin, dont témoigne (jusque sur la couverture) un nombre impressionnant de coquilles.

INDEX

Thèmes : 13.1. Iran

\section{AUTEURS}

JEAN-PIERRE DIGARD

CNRS - Paris 